\title{
Ação in vitro de fontes de silício sobre isolados de Curtobacterium flaccumfaciens pv. flaccumfaciens
}

\author{
Renato Anastácio Guazina ${ }^{1}$; Gustavo de Faria Theodoro ${ }^{2}$
}

\begin{abstract}
${ }^{1}$ Doutorando em Agronomia, Universidade Federal da Grande Dourados (UFGD). ${ }^{2}$ Professor Associado, Universidade Federal de Mato Grosso do Sul (UFMS).

Autor para correspondência: Renato Anastácio Guazina (renato@guazina.com)

Data de chegada: 5/05/2016. Aceito para publicação em: 13/07/2017.
\end{abstract}

$10.1590 / 0100-5405 / 2186$

\section{RESUMO}

Guazina, R.A.; Theodoro, G.F. Ação in vitro de fontes de silício sobre isolados de Curtobacterium flaccumfaciens pv. flaccumfaciens. Summa Phytopathologica, v.43, n.4, p.310-315, 2017.

O objetivo deste estudo foi avaliar a ação in vitro do silicato de potássio e de alumínio, em várias concentrações $(0,0 ; 0,5 ; 1,0 ; 1,5 ; 2,0 ; 2,5 ; 3,0$ e 10,0 \%), sobre dez isolados de Curtobacterium flaccumfaciens pv. flaccumfaciens (Cff). O fungicida tolylfluanid foi utilizado como testemunha positiva. Os discos de papel embebidos nos produtos, em diferentes concentrações, foram colocados no centro de cada placa de Petri após a solidificação do meio de cultura (NSA) contendo a bactéria e as aferições dos halos de inibição foram realizadas após 48 h de incubação. Verifícou-se que o silicato de potássio (Supa Sílica ${ }^{\circledR}$ ) não afetou o crescimento de $C f f$, enquanto que o silicato de alumínio (Rocksil ${ }^{\circledR}$ ) teve ação inibitória aos isolados avaliados.

Palavras-chave: murcha-de-curtobacterium, silicato de potássio, silicato de alumínio

\section{ABSTRACT}

Guazina, R.A.; Theodoro, G.F. In vitro action of silicon sources on isolates of Curtobacterium flaccumfaciens pv. flaccumfaciens. Summa Phytopathologica, v.43, n.4, p.310-315, 2017.

The aim of this study was to evaluate the in vitro action of potassium and aluminum silicate, at various concentrations $(0.0,0.5,1.0,1.5,2.0,2.5,3.0$ and $10.0 \%)$, on isolates of Curtobacterium flaccumfaciens pv. flaccumfaciens (Cff). The fungicide tolylfluanid was used as a positive control. Paper discs embedded with the test compounds at different concentrations were placed in the center of each Petri dish after solidification of the culture medium (NSA) containing the bacterium, and the measurements of inhibition halos were performed after $48 \mathrm{~h}$ incubation. Potassium silicate (Supa Sílica ${ }^{\circledR}$ ) did not affect the growth of $C f f$, while the aluminum silicate (Rocksil ${ }^{\mathbb{}}$ ) had an inhibitory action on the evaluated isolates.

Keywords: bacterial wilt, potassium silicate, aluminum silicate

A murcha-de-curtobacterium foi reportada causando sérios danos em diversas regiões produtoras de feijão no Brasil. Recentemente foi constatado por Theodoro et al. (28) a primeira ocorrência da doença no Estado de Mato Grosso do Sul, em lavoura comercial no município de Chapadão do Sul, durante a safra 2009/10. Esta doença é causada pela bactéria Curtobacterium flaccumfaciens pv. flaccumfaciens (Cff) e causa os sintomas de escurecimento vascular, murcha, amarelecimento de folhas, subdesenvolvimento e morte das plantas (26); em decorrência do patógeno colonizar os vasos do xilema e obstruir a passagem de seiva (16). Após a morte da planta a bactéria pode permanecer nos restos de cultura, quando mantidos na superfície do solo, tornando-se uma importante fonte de inóculo (22). Outros meios de sobrevivência são em hospedeiros alternativos, como em outras leguminosas, por exemplo, em feijão-caupi e soja $(19,23)$ e na própria semente $(15)$, tornando-se além de fonte de inóculo, principal meio de disseminação do patógeno (10).

O manejo da doença se baseia, fundamentalmente, em medidas preventivas, como na rotação de cultura, incorporação de restos culturas, uso de cultivares resistentes e de sementes sadias (29). A dificuldade dos produtores em encontrar cultivares de feijoeiro resistente ao patógeno para uma determinada região e até mesmo na aquisição de sementes certificadas livres do patógeno tem despertado o interesse de pesquisadores em buscar novas alternativas de controle para a doença. A erradicação da $C f f$ em sementes de feijoeiro utilizando a termoterapia foi relatado por Estafani et al. (7) como uma técnica promissora, porém, apresentando inconvenientes de não ser simples quando realizado em um grande volume de sementes. Os autores ainda relatam que a erradicação utilizando o produto químico Agrimaicin não foi efetiva em sementes inoculadas, provavelmente pela alta concentração da bactéria. Já em experimento realizado por Metha et al. (18), o uso do fungicida tolylfluanid, na concentração de $4.508 \mu \mathrm{g} \cdot \mathrm{mL}^{-1}$, demonstrou alta eficiência na erradicação da bactéria em sementes de feijoeiro naturalmente infectadas, apresentando ação bactericida contra $C f f$. Apesar da comprovação de sua eficiência o fungicida tolylfluanid não é registrado no Ministério da Agricultura, Pecuária e Abastecimento (MAPA) para a cultura do feijoeiro.

A nutrição mineral utilizada de forma equilibrada, juntamente com outros métodos de controle, pode contribuir para o controle de doenças em diversas culturas $(8,13)$. O silício ( $\mathrm{Si}$ ) tem sido bastante estudado e apesar de não ser um nutriente essencial às plantas, têm trazido benefícios a várias espécies (20). Entre estes, o Si parece ativar mecanismos de defesa em resposta ao ataque de patógenos 
nas plantas, como o aumento na síntese de compostos fenólicos e das enzimas peroxidase, polifenoloxidase e quitinase (25); além de induzir o fortalecimento da parece celular, com o aumento do teor de lignina, dificultando a penetração de patógenos na planta hospedeira $(12,21)$, contribuindo na redução de componentes epidemiológicos como o índice de esporulação, número total de pústula e severidade da doença (5).

Resultados promissores também foram relatados com doenças bacterianas em algumas espécies vegetais. Dannon \& Wydra (6) observaram redução na incidência de Ralstonia solanacearum em plantas de tomateiro crescidas em solução nutritiva contendo Si. Outro efeito positivo foi observado em plantas de citros onde o fornecimento metassilicato de sódio, via solo, reduziu os sintomas da clorose variegada do citros (CVC), causado pela Xylella fastidiosa subsp. pauca (17). Em plantas de meloeiro amarelo, o silício reduziu significativamente o índice de doença, causada por Acidovorax avenae subsp. citrulli (9). Na cultura do algodoeiro observou-se redução da severidade da mancha angular, causada por Xanthomonas axonopodis pv. malvacearum (14).

Brancaglione et al. (4) relatam o controle preventivo e curativo da bacteriose do maracujazeiro quando as plantas foram tratadas com silício. No mesmo experimento os autores observaram, in vitro, inibição de até $100 \%$ do crescimento de Xantomonas axonopodis pv. passiflore, nos tratamentos onde adicionaram argila silicatada, confirmando a ação antibacteriana do produto. Albuquerque \& Uesugi (2) também verificaram a mesma ação de silício sobre Xanthomonas axonopodis pv. citri, agente causal do cancro cítrico, cuja inibição foi obtida em concentrações superiores a $1 \%$.

Diante do potencial antibacteriano deste elemento mineral, o objetivo deste trabalho foi avaliar a ação in vitro do silicato de potássio e alumínio, em várias concentrações $(0,0 ; 0,5 ; 1,0 ; 1,5 ; 2,0 ; 2,5 ; 3,0$ e 10,0\%), sobre Curtobacterium flaccumfaciens pv. flaccumfaciens.

\section{MATERIAL E MÉTODOS}

O experimento foi conduzido no Laboratório de Fitopatologia da Universidade Federal de Mato Grosso do Sul (UFMS), Câmpus de Chapadão do Sul.

Os isolados de Cff foram obtidos da coleção do Laboratório de Fitopatologia da UFMS, totalizando 10 isolados, oriundos de feijoeiro, dos Estados de Mato Grosso do Sul, Goiás, São Paulo, Paraná e Santa Catarina (Tabela 1).

Utilizou-se como fonte de silício os produtos comerciais Supa Sílica $^{\circledR}$ (silicato de potássio) e Rocksil ${ }^{\circledR}$ (silicato de alumínio). A descrição dos produtos segue na Tabela 2 .

Para cada isolado de Cff foi realizado um experimento em delineamento inteiramente casualizado, seguindo o esquema fatorial [(2x8)+1], perfazendo 17 tratamentos, constituídos pela combinação de duas fontes de silício, oito concentrações e mais um tratamento adicional (testemunha positiva). Todos os tratamentos tiveram cinco repetições.

A metodologia empregada foi semelhante àquela utilizada por Theodoro \& Maringoni (27), que consiste na deposição de discos de
Tabela 1 Relação dos isolados de Curtobacterium flaccumfaciens pv. flaccumfaciens utilizados neste estudo.

\begin{tabular}{cc}
\hline Isolados & Origem \\
\hline FJ 001 & Mato Grosso do Sul \\
FJ 004 & Paraná \\
FJ 005 & Goiás \\
FJ 007 & São Paulo \\
FJ 008 & Santa Catarina \\
FJ 009 & São Paulo \\
FJ 010 & São Paulo \\
FJ 011 & Paraná \\
FJ 013 & Santa Catarina \\
FJ 014 & Paraná \\
\hline
\end{tabular}

papel de filtro, umedecidos nas concentrações dos produtos, sobre o meio de cultura nutriente-sacarose-ágar ('NSA' - extrato de carne 3,0 g, peptona 5,0 g, ágar 15,0 g, sacarose 5,0 g, água destilada q.s.p. 1000 $\mathrm{ml}$ ), contendo a bactéria. Esta foi cultivada em meio de cultura nutriente líquido ágar ('NL'- extrato de carne 3,0 g, peptona 5,0 g, sacarose 5,0 g, água destilada q.s.p. $1000 \mathrm{ml}$ ) por $48 \mathrm{~h}$, a $25-28^{\circ} \mathrm{C}$, e essa suspensão foi misturada ao meio NSA fundente a $45-50{ }^{\circ} \mathrm{C}$, na razão de um mililitro da suspensão bacteriana para $10 \mathrm{ml}$ de meio de cultura.

Vinte milímetros dessa mistura foram transferidos assepticamente para casa placa de Petri. Após a solidificação do meio de cultura, foi depositado no centro da placa um disco de papel de filtro esterilizado, previamente embebido na suspensão dos produtos. Os produtos contendo silício foram diluídos em série em água destilada estéril e ajustados para as concentrações de 0,$0 ; 0,5 ; 1,0 ; 1,5 ; 2,0 ; 2,5 ; 3,0$ e 10,0 $\%$. O fungicida tolylfluanid foi utilizado como testemunha positiva na concentração de $4.508 \mu \mathrm{g} \cdot \mathrm{mL}^{-1}$, conforme Metha et al. (18).

Após a deposição dos discos de papel na superfície do meio de cultura, as placas de Petri foram mantidas durante $2 \mathrm{~h}$, sob refrigeração, para a difusão do produto no meio de cultura e a paralisação do crescimento bacteriano. Posteriormente, as placas de Petri foram submetidas à incubação por $48 \mathrm{~h}$, a $25-28^{\circ} \mathrm{C}$.

As avaliações de aferição do halo de inibição foram realizadas após $48 \mathrm{~h}$ de incubação, medindo os diâmetros perpendiculares dos halos, em milímetro e em cada placa de Petri. Após a aferição dos halos foram descontados $12 \mathrm{~mm}$ referente ao diâmetro dos discos de papel de filtro para então realizar análise estatística.

Os dados obtidos foram transformados para $\mathrm{x}+1$ e submetidas à análise de variância. Quando alcançada significância estatística as médias dos fatores qualitativos (fontes de silício) foram comparadas entre si pelo teste F. O efeito das concentrações das fontes silicatadas (fatores quantitativos), quando significativos, foi submetido à análise de regressão, selecionando-se a equação que melhor ajusta-se aos dados obtidos. Para comparar as concentrações com a testemunha positiva foi utilizado o teste de Dunnett. Para todos os testes realizados neste estudo foram utilizados a $5 \%$ de significância.

Tabela 2 Composição das fontes de silício utilizadas neste estudo.

\begin{tabular}{|c|c|}
\hline Produto Comercial & Composição \\
\hline Supa Sílica $^{\circledR}$ & $\mathrm{SiO}_{2} 10 \%+\mathrm{K}_{2} \mathrm{O} 23,7 \%$ \\
\hline Rocksil $^{\circledR}$ & $\mathrm{SiO}_{2} 17,43 \%+\mathrm{Al}_{2} \mathrm{O}_{3} 20,56 \%+\mathrm{S} 9,82 \%+\mathrm{CaO} 1,31 \%+\mathrm{TiO}_{2} 0,34 \%+\mathrm{MgO} 0,18 \%+\mathrm{Fe}_{2} \mathrm{O}_{3} 0,16 \%+\mathrm{P}_{2} \mathrm{O}_{5} 0,10 \%$ \\
\hline
\end{tabular}




\section{RESULTADOS E DISCUSSÃO}

Através da análise de variância verificou-se efeito significativo $(\mathrm{p}<0,05)$ na interação entre fontes $\mathrm{x}$ concentrações. Dentre as fontes, observa-se que o tratamento com silicato de potássio, independente do isolado, não apresentou ação antibacteriana, pois não promoveu inibição do crescimento, enquanto que, no tratamento com silicato de alumínio foi possível observar halos de inibição em todos os isolados de Cff. Nos isolados FJ 004 e FJ 009 houve diferença entre as fontes já nas menores concentrações $(0,5$ e $1,0 \%$, respectivamente) enquanto que nos demais isolados observou-se diferença entre as fontes nas concentrações mais altas, geralmente a partir de 1,5 a 2,0\% (Tabela 3).

Os resultados obtidos neste estudo com o silicato de potássio não corroboram com os obtidos por Anjos et al. (3) que relataram que esta fonte de Si inibiu o crescimento de Xanthomonas spp. Pouco se sabe do mecanismo de supressão do patógeno com adição de fontes de silício no meio. Uma hipótese para a explicação da supressão do patógeno e da diferença entre as fontes utilizadas neste estudo é o fato de que o produto possa apresentar em sua composição elementos tóxicos, como no caso do Rocksil ${ }^{\circledR}$ (silicato de alumínio), que além do silício contém teores de alumínio e titânio, os quais já foram reportados como sendo tóxicos às bactérias $(1,11)$.

Foi realizado análise de regressão no tratamento com silicato de alumínio, pois foi verificada ação inibitória das diferentes concentrações sobre o crescimento da bactéria. O modelo matemático foi ajustado para se obter uma equação de concentração/resposta que melhor representa-se as duas variáveis em cada isolado. Em todos os dez isolados de $C f f$ avaliados o halo de inibição respondeu de forma linear e positiva $(\mathrm{p}<0,05)$ com o aumento das concentrações utilizadas. Desse modo, nota-se que a ação inibitória depende da concentração do silicato de alumínio, o que em parte, explica o aumento do halo de inibição nas maiores concentrações desta fonte silicatada (Figura 1).

Com relação à comparação entres as concentrações do silicato de alumínio e a testemunha positiva (tolylfluanid) (Tabela 4), nota-se que apenas na maior concentração (10,0\%) mostrou diferença com o tratamento testemunha em todos os isolados de Cff. O isolado FJ 005, oriundo do Estado de Goiás, apresentou comportamento diferente em relação aos outros isolados avaliados, pois não foi sensível ao tolyfluanid, mas apresentou sensibilidade às concentrações de 2,5, 3,0 e $10 \%$ de silicato de alumínio. Os isolados FJ 004, FJ 009 e FJ 013 apresentaram sensibilidades semelhantes entre si, pois formaram halos nas concentrações de 3,0 e $10,0 \%$ de silicato de alumínio. Apesar de diferirem estatisticamente da testemunha somente na maior concentração (10\%), os isolados FJ 014 e FJ 010, apresentaram a maior sensibilidade ao silicato de alumínio, observando halos de $19,8 \mathrm{~mm}$ e $21,4 \mathrm{~mm}$, enquanto para o tolylfluanid os halos foram de $2,8 \mathrm{~mm}$ e $3,0 \mathrm{~mm}$, respectivamente, para cada isolado.

As variações na sensibilidade ao silicato de alumínio entre isolados, verificada neste estudo, sugerem a ocorrência de variabilidade genética na população de $C f f$, confirmando com as observações de Souza et al. (24). Assim, ressalta a importância do conhecimento da variabilidade genética entre populações para futuros estudos que objetivem recomendar uso de produtos.

Embora seja relatada alta atividade antibacteriana deste produto a $X$. axonopodis pv. passiflore $\mathrm{e}$. axonopodis pv. citri, inibindo 100 $\%$ o crescimento bacteriano em meios de culturas contendo baixas concentrações do produto (a partir de $0,5 \%)(2,4)$, o mesmo, não foi confirmado neste trabalho, porém, verifica-se, de modo geral, uma tendência de que quanto maior a concentração, maior é o efeito do silicato de alumínio no sentido de inibir o desenvolvimento de Cff, já que os melhores índices de inibição foram nas maiores concentrações.

Tabela 3 Halo de inibição ( $\mathrm{mm}$ ) de 10 isolados de Curtobacterium flaccumfaciens pv. flaccumfaciens com diferentes concentrações, provenientes de duas fontes de silício.

\begin{tabular}{|c|c|c|c|c|c|c|c|c|c|c|}
\hline \multirow[b]{2}{*}{ Isolados } & \multirow[b]{2}{*}{ Fontes } & \multirow[b]{2}{*}{0,0} & \multicolumn{8}{|c|}{ Concentrações (\%) } \\
\hline & & & 0,5 & 1,0 & 1,5 & 2,0 & 2,5 & 3,0 & 10,0 & CV $(\%)$ \\
\hline \multirow{2}{*}{ FJ 001} & Supa Sílica & $1,0 \mathrm{a}$ & $1,0 \mathrm{a}$ & $1,0 \mathrm{a}$ & $1,0 \mathrm{a}$ & $1,0 \mathrm{a}$ & $1,0 \mathrm{a}$ & $1,0 \mathrm{a}$ & $1,0 \mathrm{a}$ & \multirow{2}{*}{46,70} \\
\hline & Rocksil & $1,0 \mathrm{a}$ & $1,0 \mathrm{a}$ & $1,6 \mathrm{a}$ & $1,8 \mathrm{a}$ & $2,2 \mathrm{~b}$ & $2,8 \mathrm{~b}$ & $2,8 \mathrm{~b}$ & $8,4 \mathrm{~b}$ & \\
\hline \multirow{2}{*}{ FJ 004} & Supa Sílica & $1,0 \mathrm{a}$ & $1,0 \mathrm{a}$ & $1,0 \mathrm{a}$ & $1,0 \mathrm{a}$ & $1,0 \mathrm{a}$ & $1,0 \mathrm{a}$ & $1,0 \mathrm{a}$ & $1,0 \mathrm{a}$ & \multirow{2}{*}{22,94} \\
\hline & Rocksil & $1,0 \mathrm{a}$ & $1,8 \mathrm{~b}$ & $2,2 \mathrm{~b}$ & $3,0 \mathrm{~b}$ & $3,4 \mathrm{~b}$ & $3,2 \mathrm{~b}$ & $3,8 \mathrm{~b}$ & $12,2 \mathrm{~b}$ & \\
\hline \multirow{2}{*}{ FJ 007} & Supa Sílica & $1,0 \mathrm{a}$ & $1,0 \mathrm{a}$ & $1,0 \mathrm{a}$ & $1,0 \mathrm{a}$ & $1,0 \mathrm{a}$ & $1,0 \mathrm{a}$ & $1,0 \mathrm{a}$ & $1,0 \mathrm{a}$ & \multirow{2}{*}{34,99} \\
\hline & Rocksil & $1,0 \mathrm{a}$ & $1,6 \mathrm{a}$ & $2,0 \mathrm{a}$ & $2,4 \mathrm{~b}$ & $3,0 \mathrm{~b}$ & $3,4 \mathrm{~b}$ & $3,8 \mathrm{~b}$ & $11,0 \mathrm{~b}$ & \\
\hline \multirow{2}{*}{ FJ 008} & Supa Sílica & $1,0 \mathrm{a}$ & $1,0 \mathrm{a}$ & $1,0 \mathrm{a}$ & $1,0 \mathrm{a}$ & $1,0 \mathrm{a}$ & $1,0 \mathrm{a}$ & $1,0 \mathrm{a}$ & $1,0 \mathrm{a}$ & \multirow{2}{*}{29,98} \\
\hline & Rocksil & $1,0 \mathrm{a}$ & $1,6 \mathrm{a}$ & $2,4 \mathrm{~b}$ & $3,0 \mathrm{~b}$ & $3,0 \mathrm{~b}$ & $3,6 \mathrm{~b}$ & $4,0 \mathrm{~b}$ & $11,0 \mathrm{~b}$ & \\
\hline \multirow{2}{*}{ FJ 005} & Supa Sílica & $1,0 \mathrm{a}$ & $1,0 \mathrm{a}$ & $1,0 \mathrm{a}$ & $1,0 \mathrm{a}$ & $1,0 \mathrm{a}$ & $1,0 \mathrm{a}$ & $1,0 \mathrm{a}$ & $1,0 \mathrm{a}$ & \multirow{2}{*}{28,09} \\
\hline & Rocksil & $1,0 \mathrm{a}$ & $1,0 \mathrm{a}$ & $1,0 \mathrm{a}$ & $1,0 \mathrm{a}$ & $1,8 \mathrm{~b}$ & $2,6 \mathrm{~b}$ & $3,2 \mathrm{~b}$ & $10,2 \mathrm{~b}$ & \\
\hline \multirow{2}{*}{ FJ 011} & Supa Sílica & $1,0 \mathrm{a}$ & $1,0 \mathrm{a}$ & $1,0 \mathrm{a}$ & $1,0 \mathrm{a}$ & $1,0 \mathrm{a}$ & $1,0 \mathrm{a}$ & $1,0 \mathrm{a}$ & $1,0 \mathrm{a}$ & \multirow{2}{*}{32,08} \\
\hline & Rocksil & $1,0 \mathrm{a}$ & $1,0 \mathrm{a}$ & $1,4 \mathrm{a}$ & $2,2 \mathrm{~b}$ & $2,8 \mathrm{~b}$ & $3,0 \mathrm{~b}$ & $3,0 \mathrm{~b}$ & $11,6 \mathrm{~b}$ & \\
\hline \multirow{2}{*}{ FJ 010} & Supa Sílica & $1,0 \mathrm{a}$ & $1,0 \mathrm{a}$ & $1,0 \mathrm{a}$ & $1,0 \mathrm{a}$ & $1,0 \mathrm{a}$ & $1,0 \mathrm{a}$ & $1,0 \mathrm{a}$ & $1,0 \mathrm{a}$ & \multirow{2}{*}{42,26} \\
\hline & Rocksil & $1,0 \mathrm{a}$ & $1,4 \mathrm{a}$ & $2,0 \mathrm{a}$ & $2,8 \mathrm{~b}$ & $2,8 \mathrm{~b}$ & $3,0 \mathrm{~b}$ & $5,0 \mathrm{~b}$ & $21,4 \mathrm{~b}$ & \\
\hline \multirow{2}{*}{ FJ 009} & Supa Sílica & $1,0 \mathrm{a}$ & $1,0 \mathrm{a}$ & $1,0 \mathrm{a}$ & $1,0 \mathrm{a}$ & $1,0 \mathrm{a}$ & $1,0 \mathrm{a}$ & $1,0 \mathrm{a}$ & $1,0 \mathrm{a}$ & \multirow{2}{*}{46,71} \\
\hline & Rocksil & $1,0 \mathrm{a}$ & $1,6 \mathrm{a}$ & $2,6 \mathrm{~b}$ & $2,6 \mathrm{~b}$ & $3,2 \mathrm{~b}$ & $4,0 \mathrm{~b}$ & $5,6 \mathrm{~b}$ & $13,2 \mathrm{~b}$ & \\
\hline \multirow{2}{*}{ FJ 013} & Supa Sílica & $1,0 \mathrm{a}$ & $1,0 \mathrm{a}$ & $1,0 \mathrm{a}$ & $1,0 \mathrm{a}$ & $1,0 \mathrm{a}$ & $1,0 \mathrm{a}$ & $1,0 \mathrm{a}$ & $1,0 \mathrm{a}$ & \multirow{2}{*}{53,98} \\
\hline & Rocksil & $1,0 \mathrm{a}$ & $1,4 \mathrm{a}$ & $1,8 \mathrm{a}$ & $2,4 \mathrm{a}$ & $3,2 \mathrm{~b}$ & $3,4 \mathrm{~b}$ & $5,4 \mathrm{~b}$ & $15,0 \mathrm{~b}$ & \\
\hline \multirow{2}{*}{ FJ 014} & Supa Sílica & $1,0 \mathrm{a}$ & $1,0 \mathrm{a}$ & $1,0 \mathrm{a}$ & $1,0 \mathrm{a}$ & $1,0 \mathrm{a}$ & $1,0 \mathrm{a}$ & $1,0 \mathrm{a}$ & $1,0 \mathrm{a}$ & \multirow{2}{*}{48,58} \\
\hline & Rocksil & $1,0 \mathrm{a}$ & $1,2 \mathrm{a}$ & $1,8 \mathrm{a}$ & $2,4 \mathrm{a}$ & $3,2 \mathrm{~b}$ & $4,0 \mathrm{~b}$ & $5,2 \mathrm{~b}$ & $19,8 \mathrm{~b}$ & \\
\hline
\end{tabular}

Dados transformados em $\mathrm{x}+1$. Médias seguidas por letras diferentes, na coluna, diferem significativamente pelo teste $\mathrm{F}$ a $5 \%$ de probabilidade. 

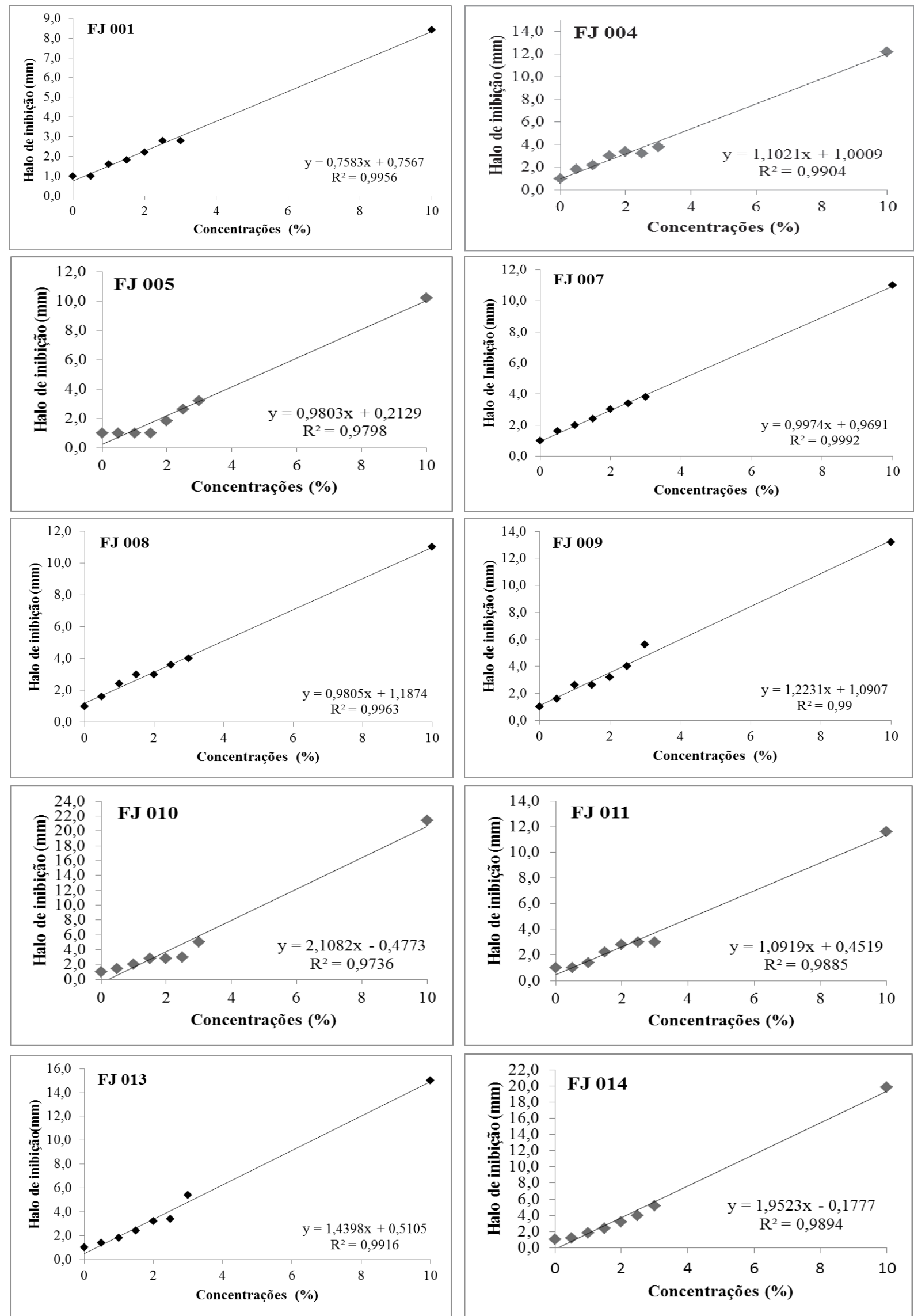

Figura 1 Inibição in vitro do crescimento de Curtobacterium flaccumfaciens pv. flaccumfaciens em diferentes concentrações do silicato de alumínio $\left(\right.$ Rocksil $\left.^{\circledR}\right)$. 
Tabela 4 Comparação da inibição de Curtobacterium flaccumfaciens pv. flaccumfaciens entre as concentrações do silicato de alumínio (Rocksil ${ }^{\mathbb{B}}$ ) e a testemunha positiva (tolylfluanid).

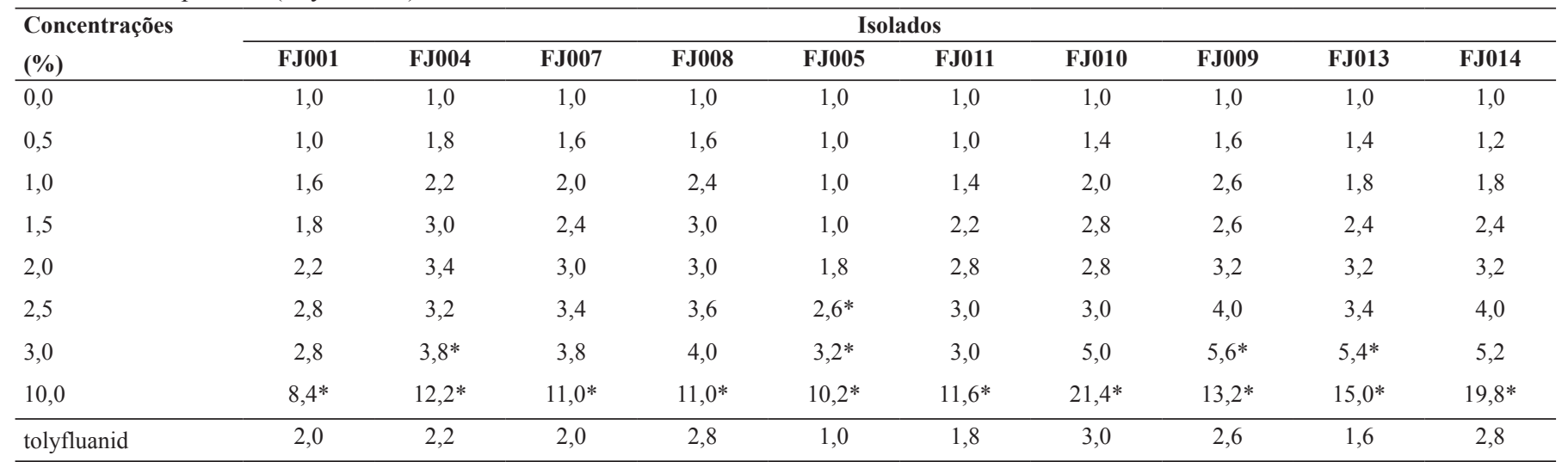

Dados transformados em $\mathrm{x}+1$. As médias seguidas por asterisco, na coluna, diferem significativamente da testemunha, a $5 \%$ de probabilidade, pelo teste de Dunnett.

\section{AGRADECIMENTOS}

Ao Conselho Nacional de Desenvolvimento Científico e Tecnológico $(\mathrm{CNPq})$, pela concessão da bolsa de iniciação científica ao primeiro autor e as empresas Pólen e Lia Agro pelo fornecimento das fontes silicatadas.

\section{REFERENNCIAS}

1. Adams, L.K.; Lyon, D.Y.; Alvarez, P.J.J. Comparative eco-toxicity of nat noscale $\mathrm{TiO}_{2}, \mathrm{SiO}_{2}$, and $\mathrm{ZnO}$ water suspensions. Water Research, Okford, v.40, n.19, p.3527-3532, 2006.

2. Albuquerque, R.C.; Uesugi, C.H. Inibição in vitro de Xanthomonas axonopodis pv. citri por Rocksil, um protetor de planta não tóxico. In: Congresso Brasileiro de Fitopalogia, 25., 2000, Belém. Anais. Brasília: Fitopatologia Brasileira, 2000. p.318.

3. Anjos, T.V.; Tebaldi, N.D.; Mota, L.C.B.; Coelho, L. Fontes de silício no controle de mancha bacteriana (Xanthomonas spp.) do tomateiro. Summa Phytopathologica, Botucatu, v.40, n.4, p.365-367, 2014.

4. Brancaglione, P.; Sampaio, A.C.; Fischer, I.H.; Almeida, A.M.; Fumis, T.F. Eficiência de argila silicatada no controle de Xanthomonas axonopodis pv. passiflorae, in vitro e em mudas de maracujazeiro-amarelo. Revista Brasileira Fruticultura, Jaboticabal, v.31, n.3, p.718-724, 2009

5. Carré-Missio,V.; Rodrigues, F.A.; Schurt, D.A.; Rezende, D.C.; Moreira, W.R; Korndörfer, D.H.; Zambolim, L. Componentes epidemiológicos da ferrugem do cafeeiro afetadas pela aplicação foliar de silicato de potássio. Tropical Plant Pathology, Lavras, v.37, n.1, p.50-56, 2012.

6. Dannon, E.A.; Wydra, K. Interaction between silicon amendment, bacterial wilt development and phenotype of Ralstonia solanacearum in tomato genotypes. Physiological and Molecular Plant Pathology, London, v.64, n.5, p.233-243, 2004.

7. Estefani, R.C.C.; Miranda Filho, R.J.; Uesugui, C.H. Tratamento térmico e químico de sementes de feijoeiro: eficiência na erradicação de Curtobacterium flaccumfaciens pv. flaccumfaciens e efeitos na qualidade fisiológica das sementes. Fitopatologia Brasileira, Brasília, v.32, n.5, p.434-438, 2007.

8. Fancelli, A.L. Micronutrientes e sua influência na ocorrência de pragas e doenças. In: Pria, M.D.; Silva, O.C. (Org.). Cultura do feijão: doenças e controle. Ponta Grossa: UEPG, 2010. p.149-168.

9. Ferreira, H.A. Silício no controle da mancha-aquosa em meloeiro (Cucumis melo L.). 2009. 82f. Dissertação (Mestrado em Fitossanidade)Universidade Federal de Pernambuco, Recife.

10. Herbes, D.H.; Theodoro, G.F.; Maringoni, A.C.; Dal Piva, C.A.; Abreu, L. Detecção de Curtobacterium flaccumfaciens pv. flaccumfaciens em sementes de feijoeiro produzidas em Santa Catarina. Tropical Plant Pathology, Lavras, v.33, n.2, p.153-156, 2008.

11. Jiang, W.; Mashayekhi, H.; Xing, B. Bacterial toxicity comparison between nano and micro-scaled oxide particles. Environmental Pollution, Amsterdam, v.157, p.1619-1625, 2009.

12. Lima, L.M.; Pozza, E.A.; Pozza, A.A.A.; Fonseca, T.A.P.S.; Carvalho, J.G Quantificação da ferrugem asiática e aspectos nutricionais de soja suprida com silício em solução nutritiva. Summa Phytopathologica, Botucatu, v.36, n.1, p.51-56, 2010.

13. Lima, L.M.; Pozza, E.A.; Torres, H.N.; Pozza, A.A.A.; Salgado, M.; Pfenning, L.H. Relação nitrogênio/potássio com mancha de Phoma e nutrição de mudas de cafeeiro em solução nutritiva. Tropical Plant Pathology, Lavras, v.35, n.4, p.223-228, 2010.

14. Mariano, R.L.R.; Oliveira, J.C.; Albuquerque, G.M.R.; Silveira, E.B. Silicato de cálcio na indução de resistência à mancha-angular do algodoeiro. Tropical Plant Pathology, Lavras, v.35, p.19, 2010. Suplemento.

15. Maringoni, A.C.; Camara, R.C. Curtobacterium flaccumfaciens pv. flaccumfaciens detection in bean seeds using a semi-selective culture medium. Brazilian Journal of Microbiology, São Paulo, v.37, n.4, p.451-455, 2006.

16. Maringoni, A.C.; Ishiszuka, M.S.; Silva, A.P.; Soman, J.M.; Moura, M.F.; Santos, R.L.; Silva Júnior, T.A.F.; Chiorato, A.F.; Carbonell, S.A.M.; Fonseca Júnior, N.S. Reaction and colonization of common bean genotypes by Curtobacterium flaccumfaciens pv. flaccumfaciens. Crop Breeding and Applied Biotechnology, Viçosa, v.15, n.2, p.87-93, 2015.

17. Martinati, J.C.; Lacava, P.T.; Miyasawa, S.K.S.; Guzzo, S.D.; Azevedo, J.L.; Tsai, S.M. Redução dos sintomas causados pela Xylella fastidiosa subsp. pauca por meio de aplicação de benzotiadiazole e silício. Pesquisa Agropecuária Brasileira, Brasília, v.42, n.8, p.1083-1089, 2007.

18. Metha, Y.R.; Alves, P.F.R.; Zandoná, C. Erradicação de Curtobacterium flaccumfaciens pv. flaccumfaciens transmitida por sementes de feijoeiro. Summa Phytopathologica, Botucatu, v. 31, p. 15, 2005. Suplemento.

19. Osdaghi, E.; Sardrood, B.P.; Bavi, M.; Oghaz, N.A.; Kimiaei, S.; Hadian, S. First report of Curtobacterium flaccumfaciens pv. flaccumfaciens causing cowpea bacterial wilt in Iran. Journal of Phytopathology, Berlin, v.163, p.653-656, 2015.

20. Pozza, E.A.; Pozza, A.A.A.; Botelho, D.M.S. Silicon in plant disease control. Revista Ceres, Viçosa, v.62, n.3, p.323-331, 2015.

21. Schurt, D.A.; Rodrigues, F.A.; Colodette, J.L.; Carré-Missio, V. Efeito do silício nas concentrações de lignina e de açúcares em bainhas de folhas de arroz infectadas por Rhizoctonia solani. Bragantia, Campinas, v.72, n.4, p.360-366, 2013.

22. Silva Júnior, T.A.F; Negrão, D.R.; Itako, A.T.; Soman, J.M.; Maringoni, A.C. Survival of Curtubacterium flaccumfaciens pv. flaccumfaciens in soil and bean crops debris. Journal of Plant Pathology, Pisa, v.94, n.2, p.331-337, 2012.

23. Soares, R.M.; Fantinato, G.G.P.; Darben, L.M.; Marcelino-Guimarães, F.C.; Seixas, C.D.S.; Carneiro, G.E.S. First report of Curtobacterium flaccumfaciens pv. flaccumfaciens on soybean in Brazil. Tropical Plant Pathology, Brasília, v.38, n.5, p.452-454, 2013.

24. Souza, V.L.; Maringoni, A.C.; Krause-Sakate, R. Variabilidade genética em isolados de Curtobacterium flaccumfacies. Summa Phytopathologica, 
Botucatu, v.32, n.2, p.170-176, 2006.

25. Tatagiba, S.D.; Rodrigues, F.A.; Filippi, M.C.; Silva, G.B.; Silva, L.C. Physiological responses of rice plants supplied with silicon to Monographella albescens infection. Journal of Phytopathology, Berlin, v.162, n.9, p.586-606, 2014.

26. Theodoro, G.F.; Maringoni, A.C. Murcha-de-Curtobacterium. In: Pria, M.D.; Silva, O.C. (Org.). Cultura do feijão: doenças e controle. Ponta Grossa: UEPG, 2010. p.23-29.

27. Theodoro, G.F.; Maringoni, A.C. Ação de produtos químicos in vitro e in vivo sobre Clavibacter michiganensis, agente causal do cancro bacteriano do tomateiro. Scientia Agrícola, Campinas, v.7, n.3, p.439-443, 2000.

28. Theodoro, G.F.; Maringoni, A.C.; Chumpati, A.A.; Correia, H.C.; Theodoro, J.V. C.; Nogueira, R.J. First report of bacteril wilt of common bean, caused by Curtobacterium flaccumfaciens pv. flaccumfaciens, in Mato Grosso do Sul, Brazil. Journal of Plant Pathology, Bari, v.92, p.110-110, 2010.

29. Valentini, G.; Guidolin, A.F.; Baldissera, J.N.C.; Coimbra, J.L.M. Curtobacterium flaccumfaciens pv.flaccumfaciens: etiologia, detecção e medidas de controle. Revista Biotemas, Florianópolis, v.23, n.4, p.1-8, 2010. 